\title{
Vitamin D-Deficiency Rickets in Two Breast-Fed Infants Who Were Not Receiving Vitamin D Supplementation
}

Patricia O'Connor, M.D.

$\mathrm{V}$ ITAMIN D-DEFICIENCY RICKETS in otherwise well infants is an easily preventaable condition which should no longer occur in this country. In 1975, two such cases of symptomatic rickets were diagnosed at the University of Michigan Hospital. These were breast-fed black infants who were not receiving vitamin D supplementation. Both cases were recognized during the winter months. Parents and health professionals should be alert to the risk of rickets in infants whose diets are not supplemented with vitamin D, either through vitamin drops or fortified milk products.

\section{Case Reports}

Case 1: A 4/2-month old black male was seen $3 / 24 / 75$ after an early-morning episode of stiffening, clonic movements, and cyanosis lasting several minutes and followed by limpness. He was born at University Hospital following a 38 -week gestation to a $G 9$ P9 mother. Birth weight was 3.15 kg. He was seen $3 / 19$ for "problem breathing"; no abnormalities were found.

On $3 / 24$ after the seizure, physical exam was normal. Weight was $6.86 \mathrm{~kg}$ (50th to 75 th percentile, Harvard growth charts). Normal results were found with CSF studies, CBC, BUN, TSP, serum albumin, and glucose. Serum calcium was

From the Pediatric Clinic, University Hospital, Ann Arbor, Mich. 48109. low $-5.4 \mathrm{mgm} \%$; phosphorus $5.0 \mathrm{mgm} \%$. He was hospitalized and treated with calcium gluconate intravenously, and phenobarbital intramusculary. EEG $3 / 25$ was mildly but definitely abnormal and paroxysmal, On interview the parents reported he had had 2 to 3 episodes since 2 weeks of age with stiffening, eye rolling, and brief apnea. He had been breast fed without vitamin supplementation. DPT and oral polio vaccine had been given on $3 / 23$. He lived in a small town. The family was intact and the father was employed.

Treatment consisted of intravenous and then oral calcium preparations, vitamin $D$, and phenobarbital. On $3 / 26$ his serum calcium was $5.6 \mathrm{mgm} \%$, phosphorus, $3.7 \mathrm{mgm} \%$, alkaline phosphatase 108 units, (normal for adults 2.5 to 11.5 units). On $3 / 28$ his calcium was $8 \mathrm{mgm} \%$. X-rays showed a poorly mineralized skull and the cupped, frayed metaphyses of rickets. He was discharged $4 / 3 / 75$, taking phenobarbital and vitamin D, $800 \mathrm{u} /$ day. When next seen on $4 / 28$ he was doing well: serum calcium was $10.1 \mathrm{mgm} \%$; phosphorus 5.3 mgm\%; alkaline phosphatase 591 units (New adult normal values $30-114$ units.); weight $8.0 \mathrm{~kg}$ (75th percentile), and length $64 \mathrm{~cm}$ (25th percentile). Diet now consisted of cereal, meat, vegetables, and milk, approximately one-half cow's milk and one-half breast milk.

Case 2: A 16-month old black girl was born 8/1/74 at University Hospital to a G3 P3 mother after a 42 -week gestation. Birth weight was 3.06 $\mathrm{kg}$. She was discharged $8 / 5$ with breastfeeding. When seen on $8 / 22$ for well child care, the examination was normal and weight was $3.5 \mathrm{~kg}$. Vitamin supplementation was advised.

She was next seen 16 months later, on $12 / 19 / 75$ 
in the orthopedic clinic because she was not walking and her wrists were thick. The clinical diagnosis of rickets was confirmed by $\mathrm{x}$-ray.

This 16-month old child, breast fed since birth, had taken no other milk and no vitamin supplements. She was a "picky eater." She had not been exposed to sunlight regularly. She lived in a small town. She had no immunizations and her parents refused these. Her parents seemed concerned, conscientious, and responsible. The family was intact and the father was employed.

On $12 / 19 / 75$ her weight was $8 \mathrm{~kg}$ ( $3 \mathrm{rd}$ percentile for 14 months); length $75 \mathrm{~cm}$ (10th percentile), and head circumference $49 \mathrm{~cm}$. The anterior fontanelle was still open, $2.5 \times 2.5 \mathrm{~cm}$. Wrists were bulbous, ankles thickened, thoracic cage pliable. She was irritable. Musculature was poorly developed. X-rays showed frayed, cupped metaphyses with wide epiphyseal plates and poorly mineralized bones. Serum calcium was $9.1 \mathrm{mgm} \%$, phosphorus $2.1 \mathrm{mgm} \%$, alkaline phosphatase 3,054 units (normal adult values $30-114$ units), BUN $6 \mathrm{mgm} \%$, TSP $7.3 \mathrm{gm} \%$, and albumin $4.9 \mathrm{gm} \%$. Hemoglobin $12.5 \mathrm{gm} \%$; WBC 10,650 ; differential 37 PMNs, 55 lymphocytes, 6 monocytes, 2 eosinophils, RBCs showed slight anisocy. tosis and poikilocytosis. Treatment with vitamin $D$, 1,600 units per day was begun. Her mother was advised to give her whole cow's milk, at least a pint daily, plus solids. Her mother wanted to continue to breast feed. On 1/5/76 her weight was $8.2 \mathrm{~kg}$; serum calcium $8.4 \mathrm{mgm} \%$; phosphorus $2.4 \mathrm{mgm} \%$; and alkaline phosphatase 2,331 units.

On $2 / 16$ the $x$-rays showed marked evidence of healing. On $4 / 17$, at 20 months, weight was 8.8 $\mathrm{kg}$ (3rd percentile for 19 months), calcium 9.0 mgm\%, phosphorus $5.5 \mathrm{mgm} \%$, and alkaline phosphatase 545 units. She was alert and walking well. She was, as usual, neatly and attractively dressed. She was no longer irritable and weak and the anterior fontanelle was closed. She was eating better but not drinking much milk. She was eating cheese and ice cream and was not being fed by breast. Her parents again refused immunizations.

\section{Discussion}

Rickets is a systemic disease primarily due to inadequate exposure of skin to ultraviolet light. On exposure to sunlight, 7-dihydrocholesterol in the skin is converted to calciferol, which is further metabolized to active forms of vitamin D. Dietary supplementation with vitamin $D$ is indicated when exposure to sunlight is insufficient to prevent rickets.

In 1927 Rosenheim and Webster demonstrated that ergocalciferol, an anti-rachitic substance, was formed when ergot, a fungus, was irradiated with ultraviolet light. ${ }^{1}$ Ergocal- ciferol is widely used in vitamin preparations and fortified foods in developed countries. Most milks, including powdered milks, produced commercially in the United States are vitamin $\mathrm{D}$ fortified. The recommended dietary allowance (RDA) of 400 IU of vitamin $D$ is to be found in one quart of fortified whole cow's milk, or fortified reconstituted powdered skim milk or commercial infant formulas. A 13-ounce can of evaporated milk contains $400 \mathrm{IU}$ of vitamin D. Cod liver oil is a natural food source of vitamin D.

Parents and health professionals should be alert to the risk of rickets in infants whose diets are not supplemented with vitamin $D$, either through vitamin drops or fortified milk products.

In spite of vitamin D fortified foods, natural food sources of vitamin D, vitamin supplements, and exposure to sunlight, the experiences here reported demonstrate that simple vitamin D-deficiency rickets can still occur in infants in this country. Dark-skinned infants in low-income northern urban areas during the winter months are at the greatest risk. In 1962 the Committee on Nutrition of the American Academy of Pediatrics ${ }^{2}$ published a survey of infantile scurvy and nutritional rickets in the United States as seen in 294 hospitals with approved pediatric residency programs. In the 226 replies, 843 cases of nutritional rickets were reported from 1956 through 1960, an incidence of 1 in 2,791 pediatric admissions to those hospitals.

Simple vitamin D-deficiency rickets was rarely diagnosed at our hospital in the $1950 \mathrm{~s}$ and 1960 s. Review of available records from 1965 to 1975 led to identification of no cases from 1965 to 1970 but of 12 cases from 1970 through 1975 . Of the 12 cases seen between 1970 and 1975,3 were nutritional rickets in potentially healthy infants. In addition to the 2 instances here reported, nutritional rickets was diagnosed in a 9-monthold psychosocially deprived white infant with growth retardation. She showed a prompt re- 
sponse to therapy and had normal growth and development at 2 years of age.

Five low-birth weight infants ( 700 to 1,300 $\mathrm{gm}), 3$ white and 2 black, developed rickets by $x$-ray and biochemically at ages 1 to 5 months. Two term infants with liver disease and cholestasis developed rickets. A 2-year old white child with malabsorption and a colostomy for Hirschprung's disease developed rickets. A 3 year-old with retardation, seizures treated with phenobarbital, poor milk intake, and no vitamin supplementation was diagnosed as having vitamin D-deficiency rickets. Nine cases were in susceptible children, three were easily preventable with the RDA of vitamin $\mathrm{D}$, 400 IU, daily.

With the two cases reported here, concerned mothers with adequate though limited financial resources were unaware of the need for vitamin supplementation for their breastfed infants. One, who rejected immunizations, was concerned about side effects of ingested or injected foreign material. With increasing concern about hazards of food additives as used in vitamin preparations, and with increasing emphasis on doing things the natural way, breast-fed infants are probably more at risk of developing vitamin D-deficiency now than in the recent past when artificial feeding and vitamin supplementation were more popular.

Our cases are not unique. Arnaud et $a l^{3}$, studying serum 25-hydroxyvitamin $D$ in infantile rickets, reported in 1974 on nine infants with nutritional rickets from Canada and the northern Midwest United States. Of these five breast-fed infants with moderate to severe rickets were 12 to 42 months of age and had had no vitamin D supplementation at the time of diagnosis. Two nonsupplemented breast-fed infants, age 2 and 6 months, who had a seizure as their major symptom, had mild to transitional rickets.

Nursing mothers should be informed of the lack of adequate vitamin $\mathrm{D}$ in their breast milk. Should a mother be reluctant to give her infant commercial multivitamin preparations that contain artificial flavoring or sweet- eners or coloring material, alternate sources of vitamin D can be prescribed. Exposure to sunlight should result in adequate vitamin D in summer months and in southern states. Considering the variables of season, latitude, air pollution, and skin pigmentation, recommended daily allowances of sunlight are not defined. Fomon cautions against reliance on exposure to sunlight in the first year of life and advises providing infants with $400 \mathrm{IU}$ of vitamin D daily from foods and "when necessary a vitamin supplement."

Exogenous sources provide reliable quantities of vitamin D. Cod liver oil can be used. According to Fourman ${ }^{5}$ cod liver oil may contain 650 units per teaspoon. Egg yolk contains approximately 200 IU of vitamin D per 100 gm. ${ }^{4}$ Drisdol, ${ }^{*}$ which is ergocalciferol USP in propylene glycol, $200 \mathrm{IU}(5 \mathrm{mg})$ per drop, $40 \mathrm{drops} / \mathrm{ml}$, may be more acceptable to mothers than multivitamin preparations which contain additives and other vitamins not needed by the infant.

In a recent restatement of its position on breastfeeding, the Committee on Nutrition of the American Academy of Pediatrics ${ }^{6}$ stressed the importance of encouraging breastfeeding but did not restate the need for vitamin $D$ supplementation in breast-fed infants. Recommendations to provide 400 IU of vitamin $D$ daily to all infants merit emphasis.

\section{References}

1. Loomis, W. F.: Rickets. Sci. Am. 223: 76, 1970.

2. American Academy of Pediatrics, Committee on $\mathrm{Na}$ trition: Infantile scurvy and nutritional rickets in the United States. Pediatrics 29, 646, 1962.

3. Amaud, S. D., Stickler, G. B., Haworth, J C.: Serum 25-hydroxyvitamin $D$ in infantile rickets. Pediatrics 57: 221,1976 .

4. Fomon, S. J Infant Nutrition, 2nd ed. Philadelphia, Saunders, 1974, pp. 216-217.

5. Fourman, $P$, Rover, P.: Calcium Netabolism and the Bone, 2nd ed Philadelphia, F. A Davis Co., 1968, p. 114

6. American Academy of Pediatrics, Committee on $\mathrm{Nu}$ trition: Commentary on breast feeding and infant formulas, including proposed standards for formulas Pediatrics $57,278,1976$

\footnotetext{
Trademark, Winthrop Corporation.
} 